\title{
Design of a dual-band antenna for energy harvesting application
}

\author{
Maizatul Alice Meor Said ${ }^{1}$, Syed Mohd Iqwan Naqiuddin Syed Jaya ${ }^{2}$, Zahriladha Zakaria ${ }^{3}$, Mohamad \\ Harris Misran ${ }^{4}$, Mohd Muzafar Ismail ${ }^{5}$ \\ ${ }^{1,2,3,4}$ Centre for Telecommunication Research \& Innovation (CeTRI), Faculty of Electronics and Computer Engineering, \\ Universiti Teknikal Malaysia Melaka, Hang Tuah Jaya, Melaka, Malaysia \\ ${ }^{5}$ Fakulti Teknologi Kejuruteraan Elektrikal dan Elektronik (FTKEE), UTeM, Malaysia
}

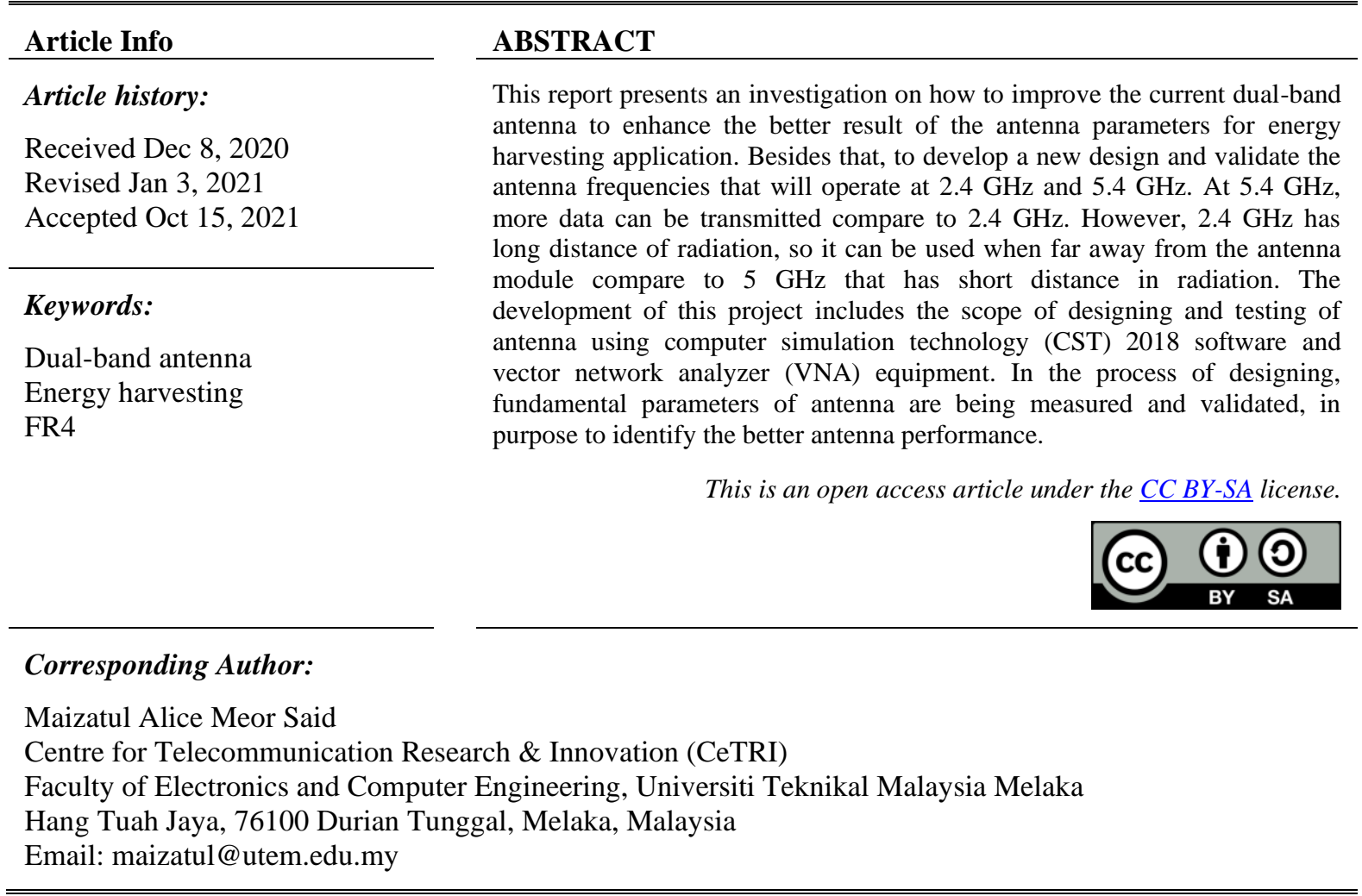

\section{INTRODUCTION}

There are variety of antenna currently existing that can be classified into deferent type of parameters and different applications [1]. Unlike some of antenna such as dipole and monopole antenna which possess narrow bandwidth characteristics, it radiates only into the space above the ground plane, or half the space of a dipole antenna, a monopole antenna will have a gain of twice ( $3 \mathrm{~dB}$ greater than) the gain of a similar dipole antenna, and a radiation resistance half that of a dipole. This project is using microstrip patch antenna (MPA) technique that implies the features of low profile, low cost, lightweight, compactness, and compatibility makes it a better option in designing a better antenna for energy harvesting compare to another substrate [2]. Besides that, the physical configurations of the antenna and the material properties of elements also contribute to the performance of the antenna. This project is divided into two main parts, software, and hardware. For the software part, the antenna is developing using computer simulation technology (CST) 2016. Then for hardware part, vector network analyzer (VNA) is used with the microstrip patch antenna [3]-[11].

Energy scavenging or power harvesting is the changes of surrounding energy sources from the human activity environment to electric power, purposely to power compact autonomous devices of electronic wirelessly. Harvesting of power energy wirelessly context is defined. Two main subsystems involved in energy harvesting system. The receiving antenna is the first component in the energy harvesting system. All the ambient energy can be from magnetic fileds or stray electric or radio waves from nearby electrical equipment will be captured by the 
receiving antenna and the integrated embedded system will be power up by this energy. This concept and technology also provide improved reliability and also creates significant cost savings for a long period of time monitoring applications. This type class of antenna design would be useful in any transmission systems whenever the increase of ambient RF energy sources can be tolerated, and also when the RF-DC power conversion efficiency are primary concerns, such as in the case of emergency relief, agricultural sensors, structural health monitoring, and battery charging. For example, the prototype antenna design in this study together with rectifying circuit is best implemented in healthcare wireless sensor such as body temperature sensor, pulse and oxygen in blood sensor, patient position sensor, air flow sensor and electrocardiogram sensor in line with energy harvesting application [12]-[25].

\section{RESEARCH METHOD}

The process of the design in this work starting with research and literature review of some previous authors as stated in Table 1 as shown in. The antenna is required to be functioning a frequency $2.4 \mathrm{GHz}$ and $5.4 \mathrm{GHz}$. As for the board of antenna, FR4 substrate is chosen to fabricate the antenna due to the availability product in UTeM's lab. The dielectric constant of this substrate is, $\varepsilon \mathrm{r}$ of 4.4, dielectric height, h of $1.6 \mathrm{~mm}$ and the copper conductor with height, $\mathrm{t}$ of $0.035 \mathrm{~mm}$. The design specifications of the dual-band antenna is shown in Table 2.

Table 1. Several researchers involved in dual-band antenna designs

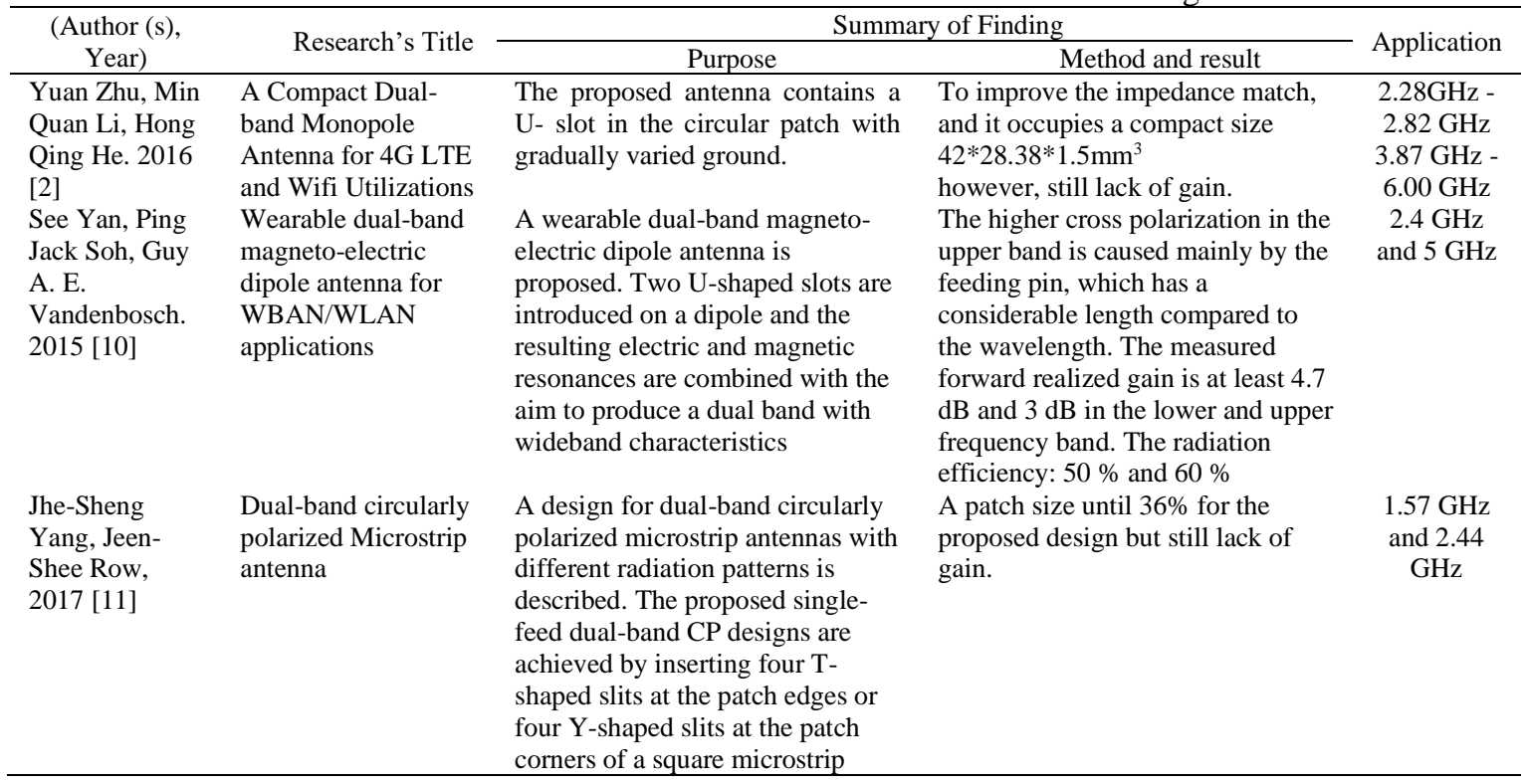

Table 2. Design specifications

\begin{tabular}{cc}
\hline Parameter & Value \\
\hline Resonant Frequency, $f_{r}(\mathrm{GHz})$ & $2.4 \mathrm{GHz}$ and $5.4 \mathrm{GHz}$ \\
Height of Copper Conductor $(\mathrm{mm})$ & $0.035 \mathrm{~mm}$ \\
Height of Substrate $(\mathrm{mm})$ & $1.6 \mathrm{~mm}$ \\
Substrate Material & FR4 with $\varepsilon_{r}$ of 4.4 \\
\hline
\end{tabular}

\subsection{Design calculation}

The calculation for width rectangular patch antenna: [1]

$$
W=\frac{C}{2 f r \sqrt{\frac{\varepsilon_{r}+1}{2}}}
$$

Where the speed of light $C=3 \times 10^{8} \mathrm{~ms}^{-1}, \mathrm{fr}=2 \cdot 4 G H_{z}$ and $\varepsilon_{r}=4.4$

$$
W=38.04 \mathrm{~mm}
$$

The effective dielectric constant, $\varepsilon_{\text {reff }}$ are to be determine using this [1] 


$$
\varepsilon_{\text {reff }}=\frac{\varepsilon_{r}+1}{2}+\frac{\varepsilon_{r}-1}{2}\left[1+12\left(\frac{h}{w}\right)\right]^{-0.5}
$$

By substituting $\mathrm{W}=38.04 \mathrm{~mm}$, and $h=1.6 \mathrm{~mm}$ and $\varepsilon_{r}=4.4$

$$
\varepsilon_{\text {reff }}=4.0858
$$

The calculation of the effective length, $L_{e f f}$ using this [1]

$$
L_{e f f}=\frac{c}{2 f_{r} \sqrt{\varepsilon_{e f f}}}
$$

Where speed of light $=3 \times 10^{8} \mathrm{~ms}^{-1}, \mathrm{fr}=2 \cdot 4 G H_{z}$ and $\varepsilon_{\text {reff }}=4.0858$

$$
L_{e f f}=30.92 \mathrm{~mm}
$$

Proceeding to the fringing length, $\Delta L$ is calculate using the formula;

$$
\Delta L=0.412 h \frac{(\varepsilon e f f+0.3)\left(\left(\frac{w}{h}\right)+0.246\right)}{\left(\varepsilon e_{f f}-0.258\right)\left(\left(\frac{w}{h}\right)+0.8\right)}
$$

By substituting $M=38.0363 \mathrm{~mm}, h=1.6 \mathrm{~mm}$ and $\varepsilon_{r}=4.4$

Lastly the actual length of the patch, $\mathrm{L}$ can be determined by using;

$$
\begin{aligned}
& L=L_{e f f}-2 \Delta L \\
& L=29.44 \mathrm{~mm}
\end{aligned}
$$

The width of the feedline is;

$$
\begin{aligned}
& B=\frac{377 \pi}{2 Z_{0} \sqrt{\varepsilon_{r}}} \\
& w f=\frac{2 h}{\pi}\left[B-1-\ln (2 B-1)+\left(\frac{\varepsilon_{r}-1}{2 \varepsilon_{r}}\left(\ln (B-1)+0.39-0.61 \varepsilon_{r}\right)\right]\right.
\end{aligned}
$$

The antenna width and length of antenna is determined by the;

$$
\begin{aligned}
& w_{g}=w+6 h \\
& L_{g}=L+6 h
\end{aligned}
$$

\subsection{Antenna structure}

Figure 1 and Figure 2 show the front and back view of the simulated antenna. Figure 3 and Figure 4 show the front and back view of the fabricated antenna. The front view and back view parameters of the simulated antenna are listed in Table 3 and Table 4.

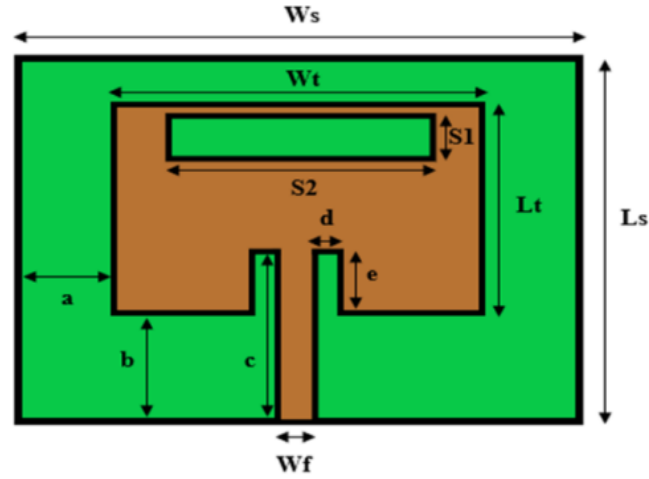

Figure 1. Front view of antenna

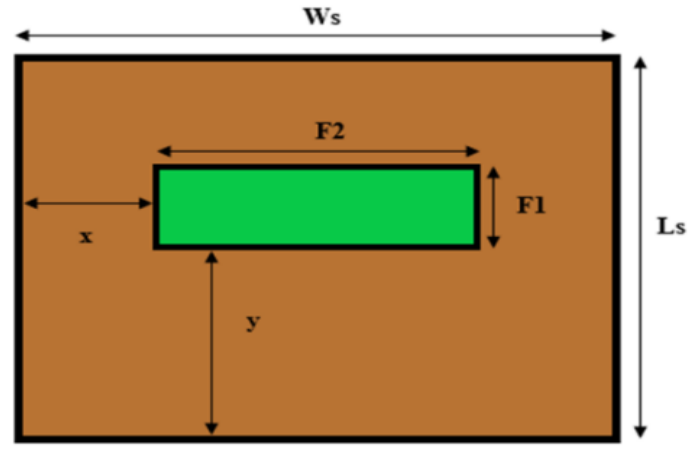

Figure 2. Back view of antenna 
Table 3. Front view parameters

\begin{tabular}{cc}
\hline Parameter & Value $(\mathrm{mm})$ \\
\hline Ws & 44.00 \\
Ls & 41.00 \\
h & 24.00 \\
Lt & 21.00 \\
Wf & 2.96 \\
S1 & 4.50 \\
S2 & 20.00 \\
a & 10.00 \\
b & 10.00 \\
c & 15.20 \\
d & 2.00 \\
e & 5.20 \\
\hline
\end{tabular}

Table 4. Back view parameters

\begin{tabular}{cc} 
Parameter & Value $(\mathrm{mm})$ \\
\hline Ws & 44.00 \\
Ls & 41.00 \\
F1 & 10.00 \\
F2 & 22.00 \\
X & 11.00 \\
y & 16.00 \\
\hline
\end{tabular}

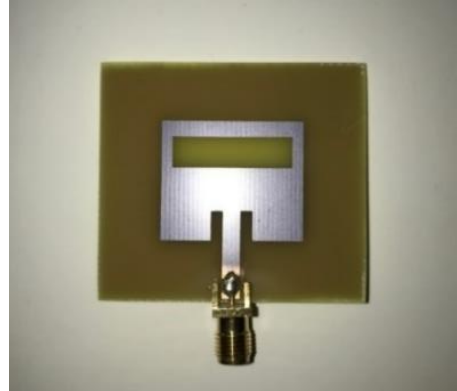

Figure 3. Front view

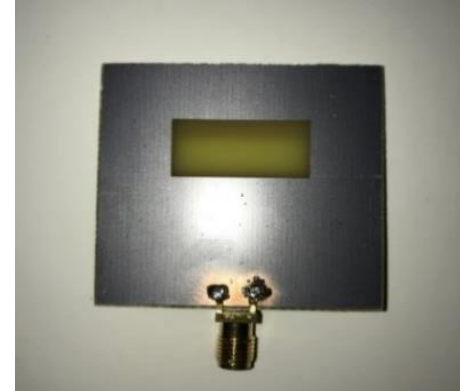

Figure 4. Back view

\section{RESULTS AND DISCUSSION}

\subsection{Farfield results}

Based on Figure 5, the simulation of the radiation pattern of the antenna at frequency $2.4 \mathrm{GHz}$ shows that the directivity is $4.623 \mathrm{dBi}$ with the efficiency of $-2.576 \mathrm{~dB}$. Based on Figure 6 , the simulation of radiation pattern of the antenna at frequency $5.4 \mathrm{GHz}$ shows that the directivity is $6.345 \mathrm{dBi}$ with the efficiency of $-3.194 \mathrm{~dB}$.

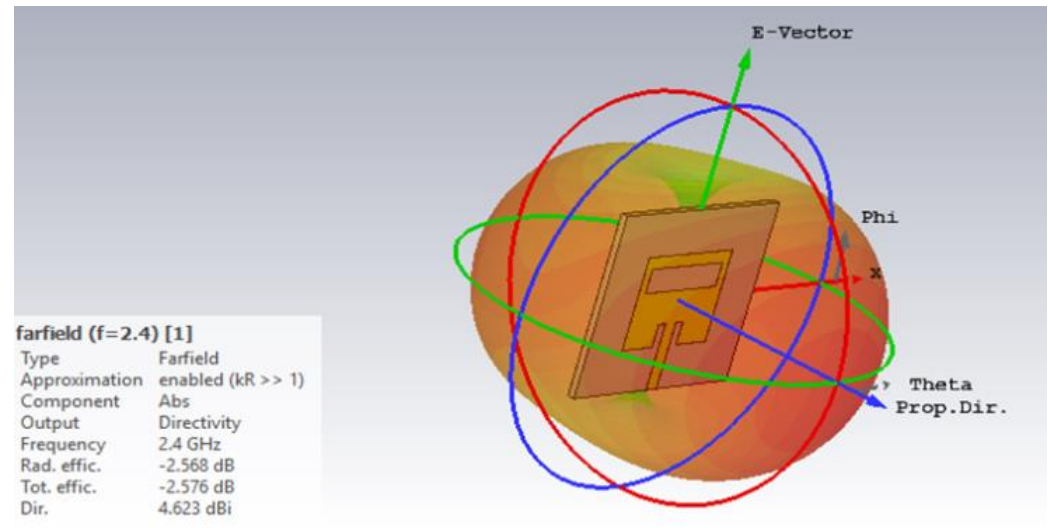

Figure 5. Farfield result at $2.4 \mathrm{GHz}$ 


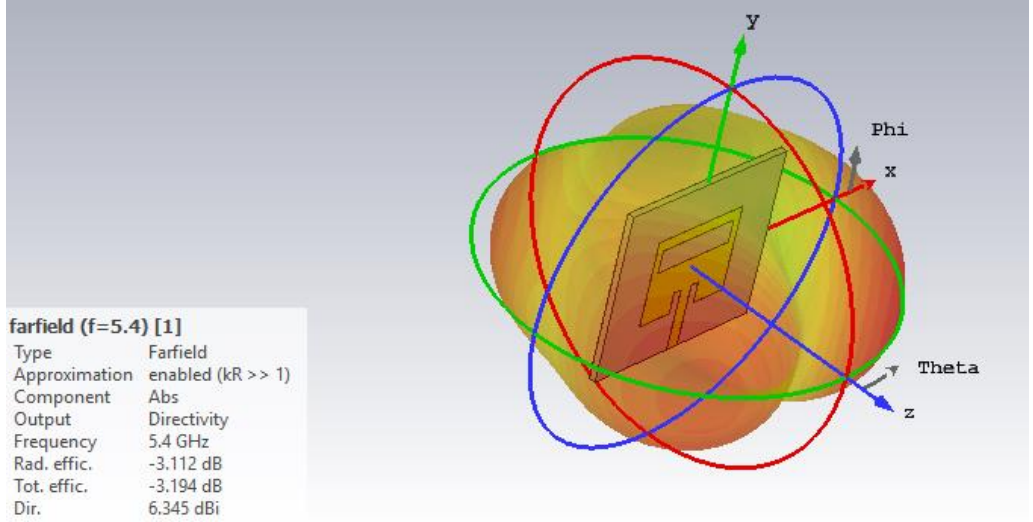

Figure 6. Farfield result at $5.4 \mathrm{GHz}$

\subsection{Gain results}

Based on Figure 7 and Figure 8, the gain for frequency $2.4 \mathrm{GHz}$ is $2.03 \mathrm{~dB}$ and for frequency 5.4 $\mathrm{GHz}$ is $3.236 \mathrm{~dB}$.

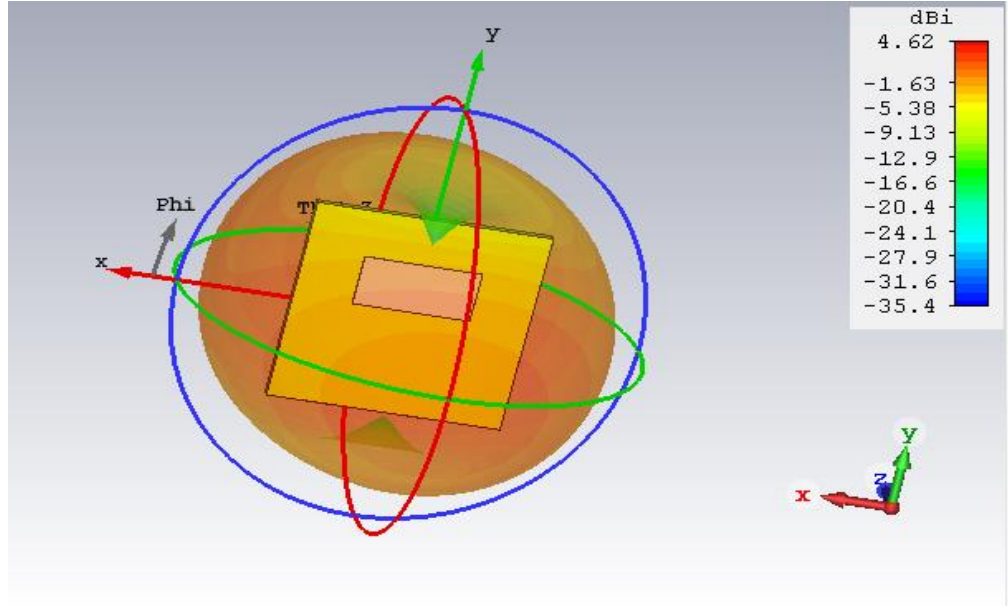

Figure 7. Gain Result for frequency $2.4 \mathrm{GHz}$

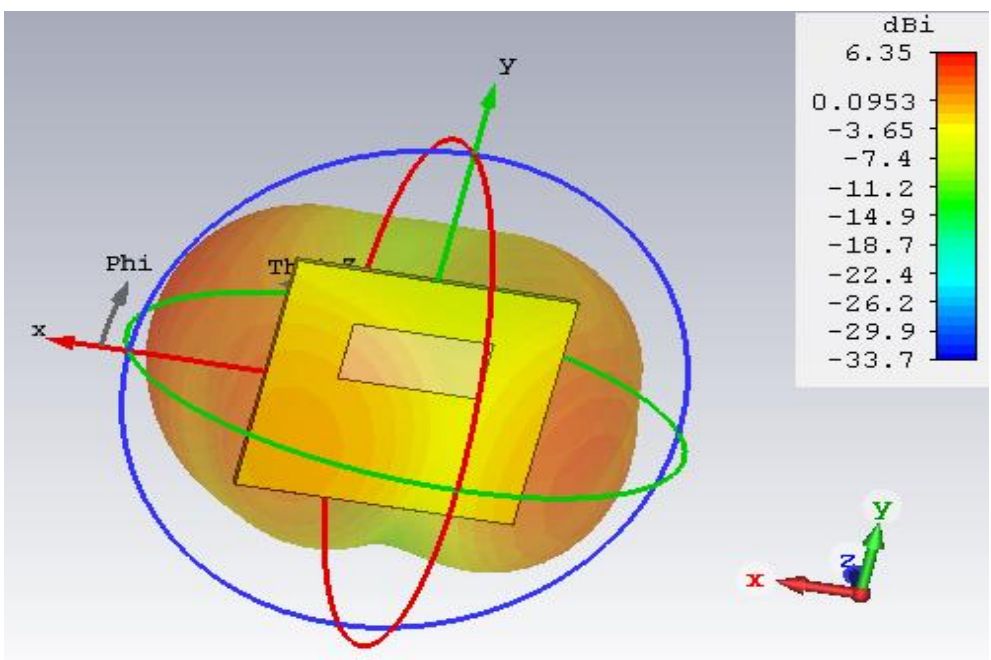

Figure 8. Gain result for frequency $5.4 \mathrm{GHz}$ 


\subsection{Result for voltage standing wave ratio (VSWR)}

Figure 9 shows the results of VSWR plot. The results show that the antenna resonated within 1.091 VSWR for $2.4 \mathrm{GHz}$ and $1.3163 \mathrm{VSWR}$ for $5.4 \mathrm{GHz}$

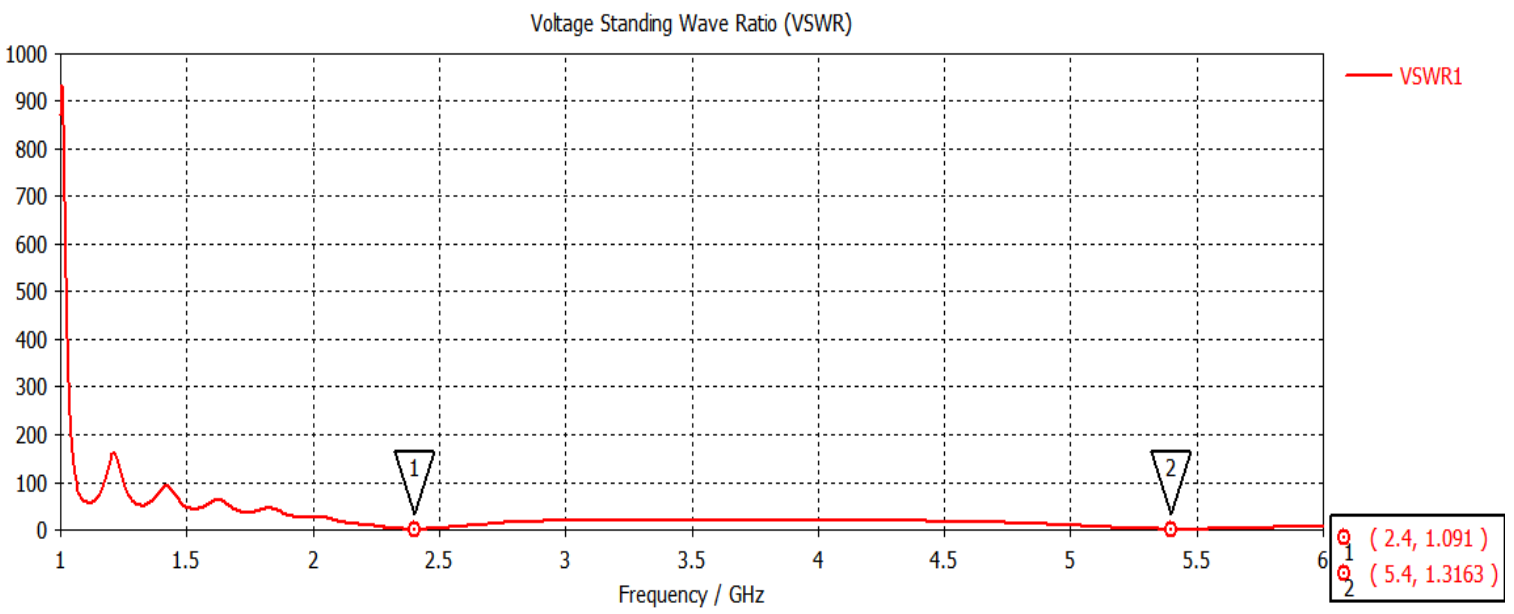

Figure 9. Result for voltage standing wave ratio (VSWR)

\section{COMPARISON BETWEEN SIMULATION AND MEASUREMENT RESULTS}

Figure 10 displays the comparison of simulated dual-band antenna at $2.4 \mathrm{GHz}$ and $5.4 \mathrm{GHz}$ designated frequencies. The simulation bandwidths for both frequencies were measured by:

Bandwidth for $2.4 \mathrm{GHz}$ is $\frac{2 \cdot 4506-2.3556}{2.4} \times 100 \%=3.96 \%$

Bandwidth for $5.4 \mathrm{GHz}$ is $\frac{5.5528-5.3407}{5.4} \times 100 \%=3.93 \%$

The measured bandwidths for both frequencies were calculated by:

Bandwidth for $2.4 \mathrm{GHz}$ is $\frac{2.4582-2.3983}{2.4} \times 100 \%=2.50 \%$

Bandwidth for $5.4 \mathrm{GHz}$ is $\frac{5.5536-5.351}{5.4} \times 100 \%=3.75 \%$

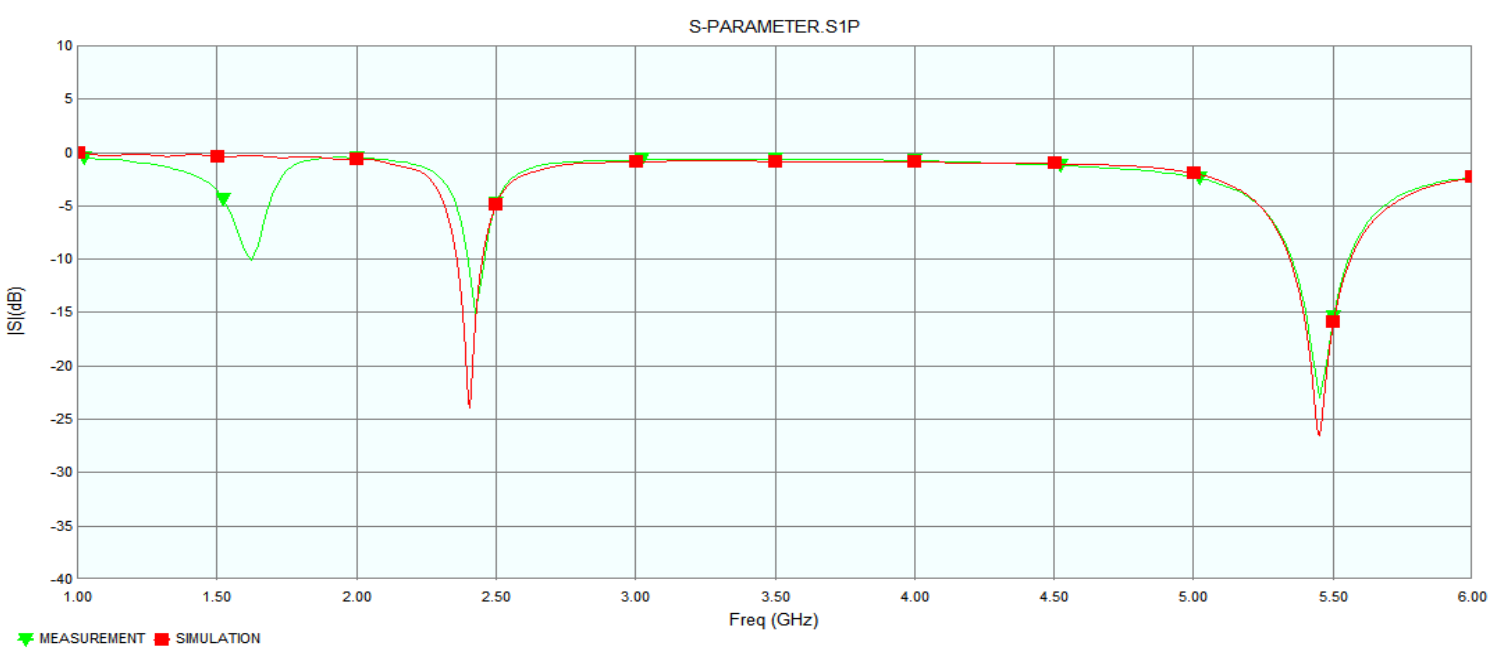

Figure 10. Comparison S-parameters results 
Table 5 shows simulation result versus measurement result for the dual-band antenna. This return loss results are acceptable for the antenna to operate. There is slight difference between the simulated antenna when compared to the measured value. This is happened maybe because in the simulation, the antenna is excited using a waveguide port, but practically the antenna is excited using the SMA connector. The connector loss has an effect on the response of the antenna, material loss, the near field scattering objects, the losses due to the feed connector and the coaxial cable also affect the response on the antenna performance and fabrication tolerance. Figures 11 and 12 show the E-plane and H-plane co-polarization at 2.4 and 5.4 $\mathrm{GHz}$ of the antenna during measurement. Both radiation patterns are observed to have monopole-like pattern.

Table 5. Simulation result versus measurement result

\begin{tabular}{lll}
\hline \multicolumn{1}{c}{ Parameter } & \multicolumn{1}{c}{ Simulation } & \multicolumn{1}{c}{ Measurement } \\
\hline First First Frequency, (f) & $2.4 \mathrm{GHz}$ & $2.4 \mathrm{GHz}$ \\
Second Frequency, (f) & $5.4 \mathrm{GHz}$ & $5.4 \mathrm{GHz}$ \\
First Return Loss (dB) & -27.23 & -15.056 \\
Second Return Loss (dB) & -30.477 & -22.967
\end{tabular}

E-plane

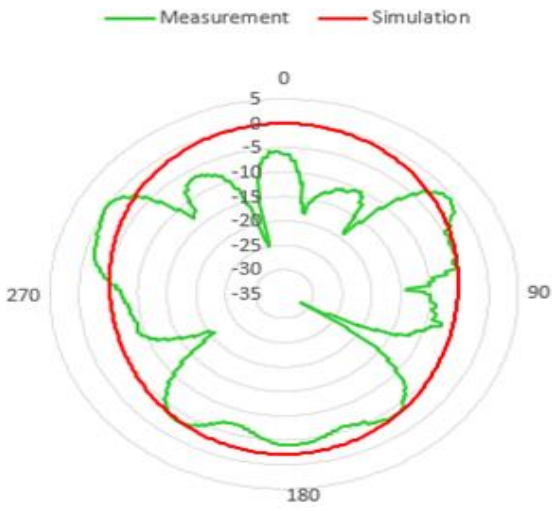

(a)

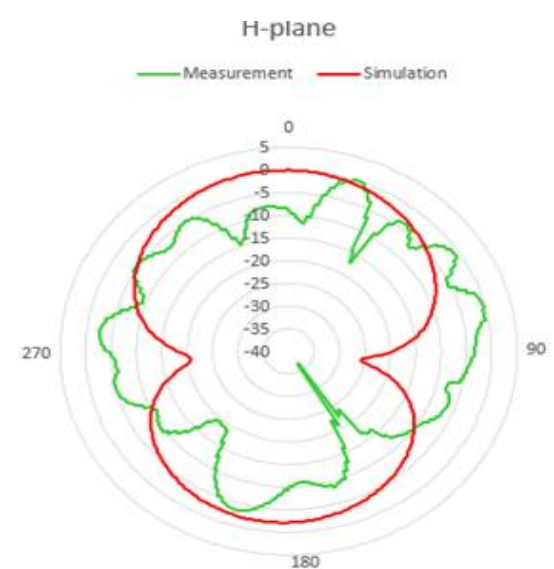

(b)

Figure 11. These figures are, (a) E-plane, (b) H-plane Co-polarization at $2.4 \mathrm{GHz}$

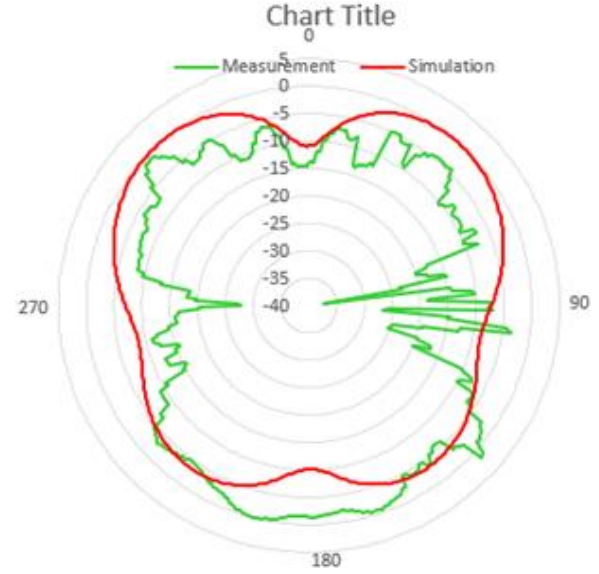

(a)

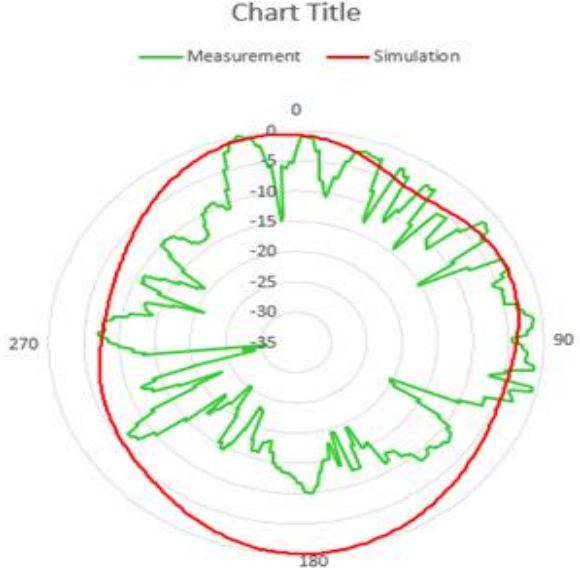

(b)

Figure 12. These figures are, (a) E-plane, (b) H-plane Co-polarization at $5.4 \mathrm{GHz}$

\section{CONCLUSION}

The purpose of this project is to investigate and develop a new dual-band antenna for energy harvesting application. Besides that, to validate the antenna frequency for dual-band antenna. The results that have obtained will indicate the performances of antenna thus the improvement of the antenna by changing the structure of the patch antenna is done. The parameters are analysed includes the return loss, the bandwidth, 
the directivity, polar gain, and VSWR of the antenna. At $5.4 \mathrm{GHz}$, more data can be transmitted compare to 2.4 GHz. However, $2.4 \mathrm{GHz}$ has long distance of radiation, so it can be use when far away from the antenna module compare to $5.4 \mathrm{GHz}$ that has short distance in radiation. The proposed design has been validated through an experiment work. The obtained results show good agreement between simulated dan measured results. Further research on this design can be carried out for triple-passband and introduce a new metamaterial antenna.

\section{ACKNOWLEDGEMENTS}

The authors gratefully appreciate the great help and useful comments of Editors and reviewers. They would also like to acknowledge the financial support by the Ministry of Education Malaysia and Universiti Teknikal Malaysia Melaka. The work was supported by UTeM under research grants RACER/2019/FKEKKCETRI/F00406.

\section{REFERENCES}

[1] F. Bian, F. Zhang, Y. Yang, Q. Zhang and J. Huang, "A compact dual band printed monopole antenna for WLAN applications," 2010 International Symposium on Signals, Systems and Electronics, 2010, pp. 1-4, doi: 10.1109/ISSSE.2010.5607097.

[2] A. Afridi, S. Ullah, S. Khan, A. Ahmed and A. H. Khalil, "Design of Dual Band Wearable Antenna Using Metamaterials," Journal of Microwave Power and Electromagnetic Energy, vol. 47, no. 2, pp. 126-137, June 2013, doi: 10.1080/08327823.2013.11689852.

[3] M. Secmen and A. Hizal, "A Dual-Polarized Wide-Band Patch Antenna for Indoor Mobile Communication Applications," Progress in Electromagnetics Research, PIER 100, pp. 189-200, 2010.

[4] S. N. S. S. Jaafar, "Design of Dual-band Microstrip Antenna," PhD Thesis. Universiti Tun Hussein Onn Malaysia, 2009.

[5] N. H. Mohd Rais, P. J. Soh, M. F. A. Malek and G. A. E. Vandenbosch, "Dual-Band Suspended-Plate Wearable Textile Antenna," in IEEE Antennas and Wireless Propagation Letters, vol. 12, pp. 583-586, 2013, doi: 10.1109/LAWP.2013.2259211.

[6] J. Xu et al., "A Wideband F-Shaped Microstrip Antenna," in IEEE Antennas and Wireless Propagation Letters, vol. 16, pp. 829-832, 2017, doi: 10.1109/LAWP.2016.2606118.

[7] S. Zhu and R. Langley, "Dual-Band Wearable Textile Antenna on an EBG Substrate," in IEEE Transactions on Antennas and Propagation, vol. 57, no. 4, pp. 926-935, April 2009, doi: 10.1109/TAP.2009.2014527.

[8] B. Garg, R. D. Verma and A. Samadhiya, "Design of Rectangular Microstrip Patch Antenna Incorporated with Innovative Metamaterial Structure for Dual band operation and Amelioration in Patch Antenna Parameters with Negative $\mu$ and $\varepsilon, "$ International Journal of Engineering and Technology, vol. 1, no. 3, pp 205-216, 2012.

[9] M. Chen and C. Chen, "A Compact Dual-Band GPS Antenna Design," in IEEE Antennas and Wireless Propagation Letters, vol. 12, pp. 245-248, 2013, doi: 10.1109/LAWP.2013.2247972.

[10] A. Narbudowicz, X. L. Bao and M. J. Ammann, "Dual-Band Omnidirectional Circularly Polarized Antenna," in IEEE Transactions on Antennas and Propagation, vol. 61, no. 1, pp. 77-83, Jan. 2013, doi: 10.1109/TAP.2012.2214992.

[11] A. K. Jassim, M. J. Farhan and A. F. Fahad, "Design Selective Band Antenna Using Coupling Sidewall and Multi Resonator for Wireless Communications," Bulletin of Electrical Engineering and Informatics (BEEI), vol. 9, no. 5, pp. 2206-2212, October 2020, doi: 10.11591/eei.v9i5.2247.

[12] J. B. Pendry, "Negative refraction males a prefect lens," Physical Review Letters, vol. 85, pp. 3966-3969, October 2020, doi: 10.1103/PhysRevLett.85.3966.

[13] B. Garg, R. Tiwari, A. Kumar and T. Chitransh, "Design of Factored "X" Shaped Metamaterial Structure for Enhancement of Patch Antenna Gain," 2011 International Conference on Communication Systems and Network Technologies, 2011, pp. 232-235, doi: 10.1109/CSNT.2011.57.

[14] J. B. Pendry, A. J. Holden, D. J. Robbins and W. J. Stewart, "Magnetism from conductors and enhanced nonlinear phenomena," in IEEE Transactions on Microwave Theory and Techniques, vol. 47, no. 11, pp. 2075-2084, Nov. 1999, doi: $10.1109 / 22.798002$.

[15] M. A. Afridi, "Microstrip patch antenna: designing at $2.4 \mathrm{GHz}$ frequency," Biological and Chemical Research, pp. 128-132, 2015.

[16] R. Garg, P. Bhartia, I. J. Bhal and A. Ittipiboon, "Microstrip Antenna Design Handbook," Artech House, 2001.

[17] E. J. Denlinger, "Radiation from Microstrip Resonators (Correspondence)," in IEEE Transactions on Microwave Theory and Techniques, vol. 17, no. 4, pp. 235-236, April 1969, doi: 10.1109/TMTT.1969.1126937.

[18] R. Mishra, "An Overview Of Microstrip Antenna," Open International Journal of Technology Innovations and Research (IJTIR), vol. 21, no. 2, pp. 1-17, August 2016.

[19] I. J. Bahl and P. Bhartia, "Microstrip Antennas," Artech House, 1980.

[20] T. Huynh and K. F. Lee, "Single-Layer-Single-Patch Wideband Microstrip Antenna," Electronics Letters, vol. 31, no. 16, pp. 1310-1312, August 1995, doi: 10.1049/el:19950950.

[21] R. M. Barrett and M. H. Barnes, “Automatic antenna wavefront plotter,” Electronics, vol. 25, pp. 120-125, 1952. 
[22] A. Yaghjian, "An overview of near-field antenna measurements," in IEEE Transactions on Antennas and Propagation, vol. 34, no. 1, pp. 30-45, January 1986, doi: 10.1109/TAP.1986.1143727.

[23] R. Devi and D. K. Neog, "Wideband planar slot antenna with a pair of E-shaped parasitic patches for wireless applications," 2016 3rd International Conference on Signal Processing and Integrated Networks (SPIN), 2016, pp. 596-599, doi: 10.1109/SPIN.2016.7566766.

[24] S. R. Saunders and A. Aragon-Zavala, "Antennas and propagation for wireless communication systems," John Wiley \& Sons, 2007

[25] J. S. Yang and J. S. Row, "Dual-band circularly polarized microstrip antenna," Microwave and Optical Technology Letters, vol. 59, no. 2, pp. 404-408, December 2016, doi: 10.1002/mop.30312.

\section{BIOGRAPHIES OF AUTHORS}
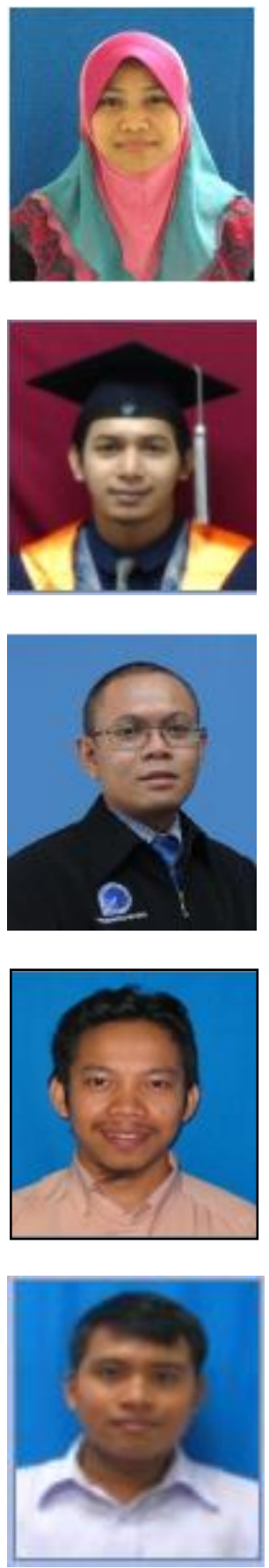

Maizatul Alice Meor Said received the BEng in Electronics Engineering (Telecommunication) from University of Surrey, UK in 2006. She obtained MEng in Master of Engineering (Telecommunication) in 2009 from University of Wollongong, Ausralia. Currently, she is a Ph.D. holder at the Universiti Teknikal Malaysia Melaka (UTeM), Melaka, Malaysia.

Syed Mohd Iqwan Naqiuddin bin Syed Jaya got his bachelor in Universiti Teknikal Malaysia Melaka. He lives in Kelantan. His area of research is antennas.

Zahriladha Zakaria is currently a Professor at Universiti Teknikal Malaysia Melaka. His research areas include microwave filters, resonators, amplifiers and antennas, data Communication and radiowave propagation in wireless communication systems.

Mohamad Harris Misran was born in Johor, Malaysia He obtained his degree in BEng in Electronics Engineering (Telecommunication) from University of Surrey, UK in 2006 and MEng in Master of Engineering (Telecommunication) in 208 from University of Wollongong, Ausralia. He is currently a full-time Ph.D. research student at the Wireless Communication Centre (WCC), Faculty of Electrical Engineering, Universiti Teknologi Malaysia (UTM), Johor, Malaysia.

Mohd Muzafar Ismail obtain his $\mathrm{PhD}$ in engineering sciences specialization atmospheric discharges. His senior lecturer at Universiti Teknikal Malaysia Melaka and research interest in electromagnetic modeling and design. 